Article

\title{
Phase-Selective Microwave Assisted Synthesis of Iron(III) Aminoterephthalate MOFs
}

\author{
Ana Arenas-Vivo ${ }^{1}\left(\mathbb{D}\right.$, David Avila $^{2}$ and Patricia Horcajada ${ }^{1, *(1)}$ \\ 1 Advanced Porous Materials Unit, IMDEA Energy. Av. Ramón de la Sagra 3, 28935 Móstoles-Madrid, Spain; \\ ana.arenas@imdea.org \\ 2 Department of Inorganic Chemistry, Chemical Sciences Faculty, Complutense University of Madrid, \\ 28040 Madrid, Spain; davilabr@ucm.es \\ * Correspondence: patricia.horcajada@imdea.org
}

Received: 28 February 2020; Accepted: 22 March 2020; Published: 23 March 2020

\begin{abstract}
Iron(III) aminoterephthalate Metal-Organic Frameworks (Fe-BDC-NH $\mathrm{NOFs}_{2}$ ) have been demonstrated to show potential for relevant industrial and societal applications (i.e., catalysis, drug delivery, gas sorption). Nevertheless, further analysis is required in order to achieve their commercial production. In this work, a systematic synthetic strategy has been followed, carrying out microwave (MW) assisted hydro/solvothermal reactions to rapidly evaluate the influence of different reaction parameters (e.g., time, temperature, concentration, reaction media) on the formation of the benchmarked MIL-101- $\mathrm{NH}_{2}$, MIL-88B-NH 2, MIL-53- $\mathrm{NH}_{2}$ and MIL-68- $\mathrm{NH}_{2}$ solids. Characterization of the obtained solids by powder X-ray diffraction, dynamic light scattering and transmission electron microscopy allowed us to identify trends to the contribution of the evaluated parameters, such as the relevance of the concentration of precursors and the impact of the reaction medium on phase crystallization. Furthermore, we presented here for the first time the MW assisted synthesis of MIL-53- $\mathrm{NH}_{2}$ in water. In addition, pure MIL-101- $\mathrm{NH}_{2}$ was also produced in water while MIL-88- $\mathrm{NH}_{2}$ was the predominant phase obtained in ethanol. Pure phases were produced with high space-time yields, unveiling the potential of MW synthesis for MOF industrialization.
\end{abstract}

Keywords: microwave synthesis; metal-organic frameworks; porous solids; iron; aminoterphthalate; phase selection

\section{Introduction}

Metal-Organic Frameworks (MOFs) are an interesting and recent family of hybrid crystalline solids based on different inorganic units connected with polydentate ligands [1]. Among other properties (e.g., optical, magnetic, electrochemical), they are notable for their impressive porosity [2,3] and their modulable chemical and topological structure [4,5]. As a result, they have an open door for their use in plenty of striking applications, both at industrial and social level, such as fluid storage and separation [6,7], catalysis [8,9], and drug delivery [10,11], among others [12].

Among the great diversity of polydentate ligands, the linear terephthatate derivatives (BDC; including the 1,4-benzene dicarboxylic acid or $\mathrm{H}_{2} \mathrm{BDC}$ and its amine substituted form $\mathrm{H}_{2} \mathrm{BDC}-\mathrm{NH}_{2}$ ) are very popular, leading to the formation of a large variety of highly porous MOF structures based on diverse cations (e.g., $\mathrm{Cu}, \mathrm{Zn}, \mathrm{Al}, \mathrm{Cr}, \mathrm{Sc}$ ) [13]. For instance, based on the earth abundant, non-toxic and redox active iron, the series of polymorphic iron(III) terephthalates MIL-53 [14], MIL-68 [15], MIL-88B [16] and MIL-101 [17] (MIL stands for Matériaux Institut Lavoisier) has been described and widely explored [18]. Briefly, MIL-101 or $\left[\mathrm{Fe}_{3} \mathrm{O}(\mathrm{OH})(\mathrm{BDC})_{3}\left(\mathrm{H}_{2} \mathrm{O}\right)_{2}\right]$ is based on iron(III) octahedra trimers ( $\mathrm{Fe}_{3}-\mu_{3}$-oxo clusters) and the $\mathrm{BDC}$, creating a rigid three-dimensional (3D) cubic MTN-zeotype structure with exceptional mesoporosity (Brunauer, Emmett \& Teller surface $\left(\mathrm{S}_{\mathrm{BET}}\right) \sim 2500 \mathrm{~m}^{2} \cdot \mathrm{g}^{-1}$, 
pore volume $\left.\left(\mathrm{V}_{\mathrm{p}}\right) \sim 2.4 \mathrm{~cm}^{3} \cdot \mathrm{g}^{-1}\right)$ with two mesocages of diameters of 29 and $34 \AA$, accessible through pentagonal and hexagonal windows of 12 and $15 \times 16 \AA$, respectively) [17]. A polymorph, also based on iron(III) octahedra trimers, is the flexible microporous MIL-88B structure $\left[\mathrm{Fe}_{3} \mathrm{O}(\mathrm{OH})(\mathrm{BDC})_{3}\left(\mathrm{H}_{2} \mathrm{O}\right)_{2}\right]$ [16] exhibiting a $3 \mathrm{D}$ hexagonal network with interconnected cages and pore channel system able to reversibly modify its size (up to $9 \AA$; with a unit cell volume variation up to $120 \%$ ) as a function of different external stimuli (e.g., adsorbate, pressure, temperature). Two additional crystalline phases can exist based on the BDC ligand but different inorganic unit, here iron(III) octahedra chains $\mathrm{FeO}_{4}(\mathrm{OH})_{2}$ : MIL-53 and MIL-68, both with the chemical formula [Fe(OH)(BDC)]. MIL-53 is a flexible 3D network with a flexible diamond shaped 1D channels [14]. This structure reaches a variation of a $40 \%$ in volume in between open (up to $8.5 \AA$ ) and closed form, depending on the guest molecules, pressure and temperature. Finally, MIL-68 is a polymorph of MIL-53, having a rigid orthorhombic structure with hexagonal $(\sim 15 \AA)$ and triangular $(\sim 5 \AA)$ shaped pores $\left(S_{\mathrm{BET}} \sim 670 \mathrm{~m}^{2} \cdot \mathrm{g}^{-1}\right)$ and its amino substituted version has not been reported for iron(III) so far [15]. These benchmarked solids have proven exceptional sorption, catalytic and photocatalytic properties [18].

Consequently, due to the interest of this family of MOFs, subsequent research on Fe-BDC- $\mathrm{NH}_{2}$ synthesis is fundamental not only for understanding the underlying formation mechanisms but also to promote facile synthetic protocols scalable for commercialization and MOF industrial application [19]. With this is mind, microwave synthesis (MW) of MOFs has been proposed as an alternative to conventional hydro- or solvothermal reactions due to several advantages: (i) energy efficiency, (ii) fast crystallization (increment in number of reaction sites), (iii) phase selectivity, (iv) high yields, (v) variety of morphologies, (vi) particle size control, (vii) lower temperatures and reaction times [20]. The conjunction of this assets dramatically increases production due to the homogeneous energy input, compared to a traditional batch reactor, which can even be enhanced by reaction stirring [21]. In addition, industrial production in the order of T.year-1 can be achieved under MW-assisted continuous flow synthesis [22]. In consonance, this technology is efficiently exploited nowadays in the production of several organic chemicals such as drugs or polymers [23,24].

Even at its infancy, MW method has become a resourceful tool for the preparation of MOFs and for their activation/purification (removing pore filling species) [20,25]. Fe-based MOFs have not been an exception and there are previous reports that focus on the MW synthesis of a particular Fe-MOF phase (mostly without substitution of the $\mathrm{H}_{2} \mathrm{BDC}$ ligand) [17,26-30]. However, as modest variations of the method lead to vast different synthetic results, a systematic study on the different variables affecting MW synthesis of iron (III) aminoterephthalate phases is still lacking. In this work, a systematic synthetic strategy has been followed, carrying out MW-assisted hydro/solvothermal reactions to rapidly evaluate the influence of different reaction parameters (e.g., time, temperature, concentration, reaction media) on the formation of the benchmarked MIL-101- $\mathrm{NH}_{2}$, MIL-88B- $\mathrm{NH}_{2}$, MIL-53- $\mathrm{NH}_{2}$ and MIL-68- $\mathrm{NH}_{2}$ solids. Crystallinity analysis as well as phase identification has been carried out by means of powder X-ray diffraction (PXRD), while particle size was investigated by dynamic light scattering (DLS) measurements and transmission electron microscopy (TEM) observation. In addition, important parameters (i.e., reaction yield and space-time yield) have been determined in order to prove the usefulness of MW synthesis for the future high scale production of Fe-BDC- $\mathrm{NH}_{2} \mathrm{MOFs}$.

\section{Materials and Methods}

\subsection{Synthesis}

Fe-BDC-NH $\mathrm{N}_{2}$ MOF structures (for codes see Table S1) were synthesized from iron(III) chloride hexahydrate $\left(\mathrm{FeCl}_{3} \cdot 6 \mathrm{H}_{2} \mathrm{O}\right.$, Sigma Aldrich, $97 \%$, Madrid, Spain), 2-aminoterephthalic acid $\left(\mathrm{H}_{2} \mathrm{BDC}-\mathrm{NH}_{2}\right.$, Acros Organics, 99\%, Geel, Belgium), ethanol (EtOH, Labkem, 96\%, Barcelona, Spain), absolute ethanol (Labkem), N,N-dimethylformamide (DMF, Acros, 99+\%, Riad, Saudi Arabia), hydrochloric acid (HCl, J.T. Baker, 37-38\%, Loughboroug, United Kingdom) and deionized water. 
Different synthetic conditions were investigated (see Tables S2-S8) for the microwave (MW) assisted-hydro/solvothermal synthesis of Fe-BDC- $\mathrm{NH}_{2}$ MOFs. In general, a reaction mixture of $4 \mathrm{~mL}$ was loaded in a $10 \mathrm{~mL}$ glass vial (G10, Anton Paar GmbH, Graz Austria) and sonicated for $1 \mathrm{~min}$ in an ultrasound bath (Branson 1800, Emerson, St. Louis, Missouri, United States) prior to being sealed and placed in a Monowave-300 MW (maximum power 300 W, Anton Paar GmbH, Graz Austria). The reactor vial in the MW was heated to the reaction temperature as fast as possible with different power impulses, maintained for a predetermined time and cooled down to $65^{\circ} \mathrm{C}$ by an air flow prior extraction of the vial from the MW. The mixture was stirred during the MW reaction at $600 \mathrm{rpm}$ at all times. As synthesized samples were recovered by centrifugation (12045 $\mathrm{g}$ for $10 \mathrm{~min}$ ) and washed three times with absolute $\mathrm{EtOH}\left(2 \mathrm{~g} \cdot \mathrm{L}^{-1}\right.$ under stirring) and recovered by centrifugation $(12045 \mathrm{~g}$ for $10 \mathrm{~min}$; activated sample, act.). Samples were stored wet in absolute $\mathrm{EtOH}$ prior to further analysis.

\subsection{Characterization}

Crystal phase of all samples was verified using powder X-ray diffraction (PXRD). PXRD patterns were collected using a conventional PANalytical Empyrean powder diffractometer (PANalytical Lelyweg, Almelo, Netherlands, $\theta-2 \theta)$ using $\lambda_{C u} K_{\alpha 1}$, and $K_{\alpha 2}$ radiation $(\lambda=1.54051$ and $1.54433 \AA)$. PXRD diagrams were carried out with a $2 \theta$ scan between $3-35^{\circ}$ with a step size of $0.013^{\circ}$ and a scanning speed of $0.1^{\circ} \cdot \mathrm{s}^{-1}$.

Particle size was monitored via dynamic light scattering (DLS using a Zetasizer Nano series Nano-ZS (Malvern Instruments, Worcestershire, UK). The solids were dispersed in the liquid media (EtOH) at a concentration of $0.1 \mathrm{mg} \cdot \mathrm{mL}^{-1}$ using an ultrasound tip (UP400S, Hilscher, Teltow, Germany) at $20 \%$ amplitude for $10 \mathrm{~s}$.

Transmission electron microscopy (TEM) images were taken with a JEM 1400 (Jeol, Tokyo, Japan) with a $120 \mathrm{kV}$ acceleration voltage (point resolution $0.38 \mathrm{~nm}$ ). For TEM studies, $1 \mathrm{mg}$ of sample was dispersed in $10 \mathrm{~mL}$ of absolute EtOH and sonicated with an ultrasound tip (UP400S, Hilscher, Teltow, Germany) at $20 \%$ amplitude for $10 \mathrm{~s}$. For observation, $1 \mu \mathrm{L}$ of the prepared solution was dropped over a copper TEM grid coated with holey carbon support film (Lacey Carbon, 300 mesh, copper, approx. grid hole size: $63 \mu \mathrm{m}$, TED PELLA Redding, CA, USA). Particle size was monitored via statistic counting $(n=70-100)$ with Image (Version 1.8.0).

To address the MW assisted reaction performance two parameters have been defined: reaction yield (wt.\%, Equation (1) and space-time yield (STY, $\mathrm{kg} \cdot \mathrm{m}^{-3} \cdot \mathrm{d}^{-1}$, Equation (2))

$$
\text { Yield }(\%)=\frac{\mathrm{m}_{\mathrm{Fe}-\mathrm{BDC}-\mathrm{NH}_{2}}}{\mathrm{~m}_{\text {theoretical }}} \times 100
$$

where $\mathrm{m}_{\mathrm{FeBDC}-\mathrm{NH} 2}$ is the experimental mass of the Fe-BDC-NH $\mathrm{N}_{2}$ MOF obtained (determined after drying at $100{ }^{\circ} \mathrm{C}$ ) and $\mathrm{m}_{\text {theoretical }}$ is the calculated theoretical amount of the determined phase that could be obtained, according to the metal used (Tables S9-S17), both in kg.

$$
S T Y=\frac{\mathrm{m}_{\mathrm{Fe}-\mathrm{BDC}-\mathrm{NH}_{2}}}{\mathrm{~V} \times \mathrm{t}}
$$

where $\mathrm{m}_{\mathrm{FeBDC}-\mathrm{NH} 2}$ is the experimental mass of the Fe-BDC-NH${ }_{2} \mathrm{MOF}$ obtained $(\mathrm{kg}), \mathrm{V}$ is the reaction volume $\left(\mathrm{m}^{3}\right)$ and $\mathrm{t}$ is the reaction time (day).

\section{Results}

$\mathrm{H}_{2} \mathrm{O}$ as reaction medium. The $\mathrm{FeCl}_{3} / \mathrm{H}_{2} \mathrm{BDC}-\mathrm{NH}_{2}$ system in water was studied under two different temperatures $\left(100\right.$ and $\left.150{ }^{\circ} \mathrm{C}\right)$ varying the iron precursor concentration $(0.02,0.05,0.1$ and $0.2 \mathrm{M}$ ). As an example, some of these conditions have been resumed in Table 1 (for further information see SI Tables S2 and S3). Under the analyzed reaction conditions, two different phases have been formed: MIL-101- $\mathrm{NH}_{2}$ and MIL-53- $\mathrm{NH}_{2}$ (Figure 1, for PXRD see Figures S1-S3). Note that it is typical to find here crystallized unreacted $\mathrm{H}_{2} \mathrm{BDC}-\mathrm{NH}_{2}$ in the as synthesized (a.s.) samples due to the poor 
solubility of the ligand in water. However, the linker excess is removed during the following activation step (see experimental section). As expected, while lower temperature led to the formation of the mesoporous MIL-101- $\mathrm{NH}_{2}$ (kinetically favored phase), at higher temperature the thermodynamic flexible microporous phase MIL-53- $\mathrm{NH}_{2}$ was formed. In addition, there is a bisectrix on the $\mathrm{T}\left({ }^{\circ} \mathrm{C}\right) /[\mathrm{Fe}]$ (M) crystallization diagram in which a mixture of phases is obtained, revealing this concentration dependency: in brief, higher concentrated reactions favor the formation of chains of corner-sharing $\mathrm{FeO}_{4}(\mathrm{OH})_{2}$ octahedra leading to MIL-53- $\mathrm{NH}_{2}$, whereas diluted conditions promote the formation of the trimer $\mathrm{Fe}_{3}-\mu_{3}$-oxo clusters and, therefore, MIL-101- $\mathrm{NH}_{2}$ crystallization.

Table 1. Mass, mol and molar ratios, and dispensed amounts for the $\mathrm{MW}$ investigation of the system $\mathrm{FeCl}_{3} \cdot 6 \mathrm{H}_{2} \mathrm{O} / \mathrm{H}_{2} \mathrm{BDC}-\mathrm{NH}_{2} / \mathrm{HCl}$ in water $\left(\mathrm{V} \mathrm{H}_{2} \mathrm{O}=4 \mathrm{~mL}, \mathrm{~T}=150{ }^{\circ} \mathrm{C}, \mathrm{t}=5 \mathrm{~min}\right.$ and $\left.{ }^{(\bullet)} \mathrm{t}=30 \mathrm{~min}\right)$.

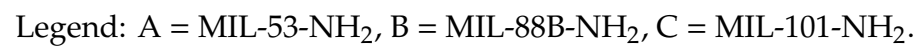

\begin{tabular}{|c|c|c|c|c|c|c|c|c|c|}
\hline $\begin{array}{l}\text { Sample } \\
\text { Name }\end{array}$ & $\begin{array}{c}\mathrm{FeCl}_{3} 6 \mathrm{H}_{2} \mathrm{O} \\
(\mathrm{mg})\end{array}$ & $\begin{array}{c}\mathrm{FeCl}_{3} 6 \mathrm{H}_{2} \mathrm{O} \\
(\mathrm{mmol})\end{array}$ & $\underset{(\mathrm{mg})}{\mathrm{H}_{2} \mathrm{BDC}^{-\mathrm{NH}_{2}}}$ & $\underset{(\mathrm{mmol})}{\mathrm{H}_{2} \mathrm{BDC}^{-\mathrm{NH}_{2}}}$ & $\begin{array}{l}\text { Ligand: } \\
\text { Metal }\end{array}$ & $\begin{array}{l}{[\mathrm{Fe}]} \\
(\mathrm{M})\end{array}$ & $\begin{array}{c}\mathrm{HCl} 1 \\
\mathrm{M}(\mathrm{mL})\end{array}$ & $\mathrm{HCl}: \mathrm{Fe}$ & Result * \\
\hline $\begin{array}{l}\text { MW } \\
2-01\end{array}$ & 21.6 & 0.08 & 14.48 & 0.08 & 1 & 0.02 & 0 & 0 & $C+A$ \\
\hline $\begin{array}{l}\text { MW } \\
2-02\end{array}$ & 54 & 0.2 & 36.2 & 0.2 & 1 & 0.05 & 0 & 0 & $A+C$ \\
\hline $\begin{array}{l}\text { MW } \\
2-03\end{array}$ & 108 & 0.4 & 72.4 & 0.4 & 1 & 0.1 & 0 & 0 & A \\
\hline $\begin{array}{c}\mathrm{MW} \\
2-04(\bullet)\end{array}$ & 108 & 0.4 & 72.4 & 0.4 & 1 & 0.1 & 0 & 0 & A \\
\hline $\begin{array}{l}\text { MW } \\
2-05\end{array}$ & 216 & 0.8 & 144.8 & 0.8 & 1 & 0.2 & 0 & 0 & $\mathbf{A}$ \\
\hline $\begin{array}{l}\text { MW } \\
2-06\end{array}$ & 54 & 0.2 & 36.2 & 0.2 & 1 & 0.05 & 0.1 & 0.5 & $C+A$ \\
\hline
\end{tabular}

${ }^{*}$ In the case of mixture, the first letter is the major phase.

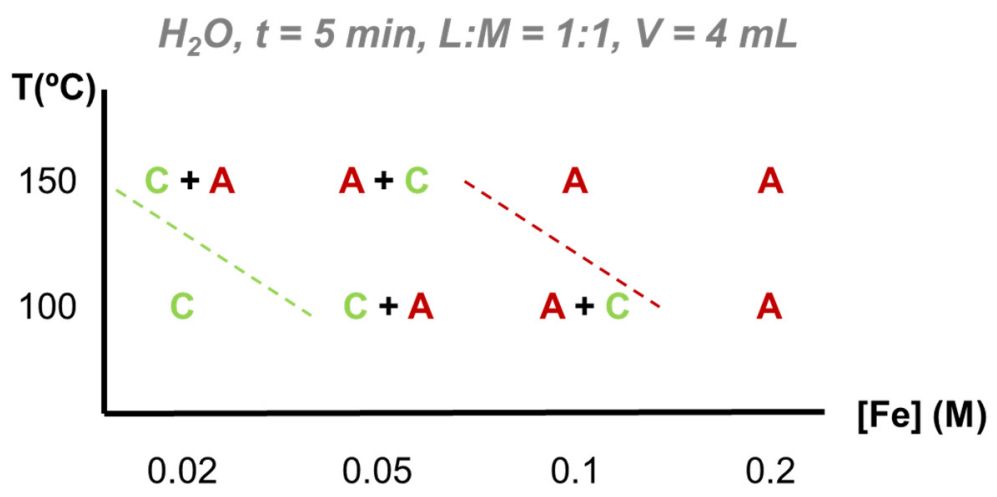

Figure 1. Crystallization diagram for the microwave (MW)-assisted hydrothermal synthesis of the system $\mathrm{FeCl}_{3} / \mathrm{H}_{2} \mathrm{BDC}-\mathrm{NH}_{2}$ in water based on powder X-ray diffraction (PXRD) data. Legend:

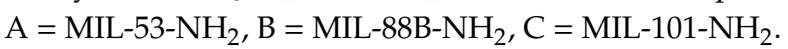

Furthermore, to evaluate the influence of the $\mathrm{pH}$ on the $\mathrm{FeCl}_{3} / \mathrm{H}_{2} \mathrm{BDC}-\mathrm{NH}_{2}$ system, the addition of the strong acid $\mathrm{HCl}$ was investigated within the region of the bisectrix, leading to mixture of MIL-53- $\mathrm{NH}_{2}$ and MIL-101- $\mathrm{NH}_{2}$ phases $\left(\mathrm{T}=100{ }^{\circ} \mathrm{C}\right.$ and $[\mathrm{Fe}]=0.05 \mathrm{M}, \mathrm{pH}$ variation from 1.5 in the reaction mixture to 1 with $\mathrm{HCl}$ ). At first glance, $\mathrm{HCl}$ presence increased the crystallinity of the Fe- $\mathrm{H}_{2} \mathrm{BDC}-\mathrm{NH}_{2}$ phases (see PXRD in Figure S3). Furthermore, one can qualitatively observe by PXRD that MIL-101- $\mathrm{NH}_{2}$ proportion seems to decrease $\left(2 \theta=4-6^{\circ}\right)$ while MIL-53- $\mathrm{NH}_{2}$ content seems to increase $\left(2 \theta=8.8\right.$ and $\left.10.1^{\circ}\right)$ with the addition of $\mathrm{HCl}$, until only MIL-53- $-\mathrm{NH}_{2}$ is produced with higher $\mathrm{HCl}$ contents $(200 \mu \mathrm{L})$.

On the whole, in water, increasing reaction temperature or increasing acidity shifts the equilibrium $\mathrm{FeCl}_{3} / \mathrm{H}_{2} \mathrm{BDC}-\mathrm{NH}_{2}$ system to the more favorable thermodynamic phase: MIL-53- $\mathrm{NH}_{2}$.

$\mathrm{EtOH}$ as reaction medium. MIL-88B- $\mathrm{NH}_{2}$ was the predominant phase observed of the $\mathrm{FeCl}_{3} / \mathrm{H}_{2} \mathrm{BDC}-\mathrm{NH}_{2}$ system when using ethanol as reaction medium (see Figure 2 and PXRD in 
Figures S4-S7). All the reaction parameters with EtOH as solvent are resumed in SI Tables S4-S6. Although, at lower temperature $\left(100^{\circ} \mathrm{C}\right)$ and longer times ( $\left.\geq 20 \mathrm{~min}\right), \mathrm{MIL}-88 \mathrm{~B}-\mathrm{NH}_{2}$ was transformed to a poorly crystalline MIL-101- $\mathrm{NH}_{2}$. In an attempt to obtain the thermodynamic MIL-53- $\mathrm{NH}_{2}$ phase as well in ethanol, the reaction temperature was increased to $180^{\circ} \mathrm{C}$. However, except for very short times $(5 \mathrm{~min})$, the increment of the reaction temperature only led to the formation of $\alpha-\mathrm{Fe}_{2} \mathrm{O}_{3}$ (rhombohedral hematite as identified by PXRD; Figure S7). This indicates that $\mathrm{Fe}_{3}-\mu_{3}$-oxo clusters are less thermodynamically favored than the iron(III) oxide under high temperatures. In addition, particle size experienced insignificant variation regardless of the conditions (Tables S12-S15), remaining below $300 \mathrm{~nm}$ with low polydispersity indexes (PdI $<0.3$ ), according to DLS measurements.

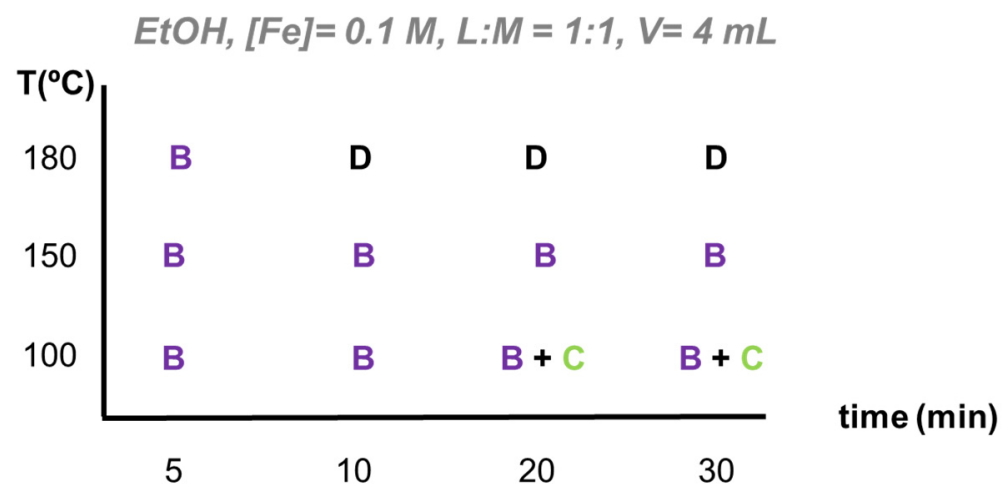

Figure 2. Crystallization diagram for the MW-assisted solvothermal synthesis of the system $\mathrm{FeCl}_{3} / \mathrm{H}_{2} \mathrm{BDC}-\mathrm{NH}_{2}$ in EtOH based on PXRD data. Legend: $\mathrm{A}=$ to MIL-53-NH $-\mathrm{B}=$ to MIL-88B-NH${ }_{2}$, $\mathrm{C}=$ to $\mathrm{MIL}-101-\mathrm{NH}_{2}, \mathrm{D}=\mathrm{Fe}_{2} \mathrm{O}_{3}$.

$\mathrm{DMF}$ as reaction medium. The different reaction parameters using DMF can be consulted in SI Tables S7 and S8. In contrast with water and $\mathrm{EtOH}$, the study of the $\mathrm{FeCl}_{3} / \mathrm{H}_{2} \mathrm{BDC}-\mathrm{NH}_{2}$ system in $\mathrm{DMF}$ in $\mathrm{MW}$-assisted solvothermal synthesis did not lead to the formation of any solid at $\mathrm{T}=100^{\circ} \mathrm{C}$. Even at $150^{\circ} \mathrm{C}$, short times under MW ( $5 \mathrm{~min}$ ) only led to the formation of poorly crystalline solids. Increasing the time promotes the formation of the MIL-101- $\mathrm{NH}_{2}$, favored phase in DMF as it was present at all tested concentrations in DMF (see Figure 3 and PXRD Figures S8-S10). This need of extra-temperature could be explained because of the higher activation energy for the $\mathrm{Fe}_{3}-\mu_{3}$-oxo cluster to bond $\mathrm{H}^{-} \mathrm{BDC}-\mathrm{NH}_{2}$ in DMF, compared to previously studied solvents (i.e., water and ethanol). Remarkably, at a concentration range $0.05-0.1 \mathrm{M}, \mathrm{MIL}-101-\mathrm{NH}_{2}$ coexists with its polymorph MIL-88B-NH ${ }_{2}$, while at higher concentration $(0.2 \mathrm{M})$ chain-based MIL-53- $\mathrm{NH}_{2}$ appears. Results suggest that DMF is a more complex reaction medium, being the only one in which three Fe-BDC- $\mathrm{NH}_{2} \mathrm{MOF}$ phases were obtained.

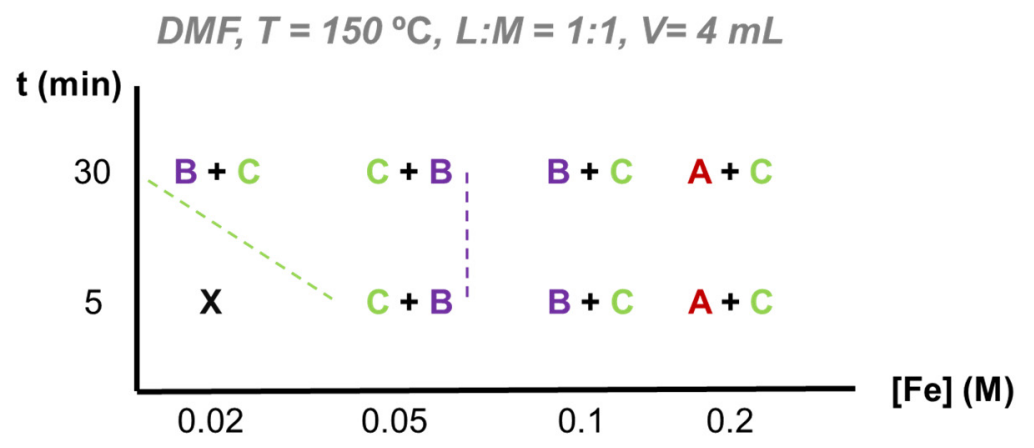

Figure 3. Crystallization diagram for the microwave-assisted solvothermal synthesis of the system $\mathrm{FeCl}_{3} / \mathrm{H}_{2} \mathrm{BDC}-\mathrm{NH}_{2}$ in DMF based on PXRD data. Legend: $\mathrm{A}=$ to MIL-53-NH, $\mathrm{B}=$ to MIL-88B-NH , $\mathrm{C}=$ to MIL-101- $\mathrm{NH}_{2}, \mathrm{X}=$ amorphous. 


\section{Discussion}

In the course of this study, 46 individual reaction mixtures (with replicates to ensure reproducibility) were carried out in three different protic and aprotic polar solvents $\left(\mathrm{H}_{2} \mathrm{O}, \mathrm{EtOH}\right.$ and DMF) using the MW-assisted solvothermal method. Water and ethanol have been selected as good examples of green chemistry reaction solvents. DMF has been selected as a typical reaction medium traditionally used in MOF solvothermal synthesis. Remarkably, the MW irradiation is a simple procedure that enables the fast and efficient attainment of three different Fe-BDC- $\mathrm{NH}_{2}$ crystalline phases by slight modifications on the synthetic conditions, reaching high reaction yields and space-time-yield (STY) comparable to those of industrial process in the market in very short times. Thus, the influence of different parameters (i.e., solvent, temperature, reaction time, molar ratio of metallic precursor and organic ligand, concentration of the reaction mixture and the addition of $\mathrm{HCl}$ ) on the product formation is here discussed as a function of the sample purity and crystallinity, crystals dimension (including size distribution), reaction yield and STY. The purity and crystallinity of the MW-assisted experiments are discussed on the basis of PXRD (see Supporting information (SI) Section 2) and are schematically represented above in crystallization diagrams. The proportion of the starting reagents and the conditions of synthesis are given in the SI (see Tables S2-S8).

$\mathrm{H}_{2} \mathrm{O}$ as reaction medium. Using water, pure MIL-101- $\mathrm{NH}_{2}$ is only obtained at low temperature and concentration $\left(100{ }^{\circ} \mathrm{C}, 0.02 \mathrm{M}\right)$, while single MIL-53- $\mathrm{NH}_{2}$ crystallizes at higher concentrations and temperature $\left(0.1 \mathrm{M}\right.$; and at $0.2 \mathrm{M}$ with both 100 and $\left.150^{\circ} \mathrm{C}\right)$. In addition, the formation of pure MIL-101- $\mathrm{NH}_{2}$ in water gave to an extremely high reaction yield (almost complete reaction $\sim 100 \%$ ) with however, lower STY associated with the diluted starting concentration $\left(3850 \mathrm{~kg} \cdot \mathrm{m}^{3} \cdot \mathrm{d}^{-1}\right.$ at $\left.0.02 \mathrm{M}\right)$. MIL-53- $\mathrm{NH}_{2}$, besides being the thermodynamically stable phase, was produced as a pure phase in lower yields ( $<70 \%$; see Table S9). However, considering the higher concentration of the reaction mixture, STY values reached $10400 \mathrm{~kg} \cdot \mathrm{m}^{3} \cdot \mathrm{d}^{-1}$, being competitive with the reported production of different MOFs (STY for Basolites ${ }^{\complement} \sim 3000 \mathrm{~kg} \cdot \mathrm{m}^{3} \cdot \mathrm{d}^{-1}$ ) $[19,31]$.

Particle size determination, by means of DLS, gave a rough estimation of the particle size of $300 \pm 100 \mathrm{~nm}$, with no clear dependence with temperature neither with concentration. Here, it should be taken into account that DLS provides information of hydrodynamic size, which can lead to misinterpretation in the case of non-spherical particles, such as $\mathrm{MIL}-53-\mathrm{NH}_{2}$, and with a mixture of different phases, as in this study. In addition, the pure MIL-53- $\mathrm{NH}_{2}$ phase obtained in water with the highest STY $\left(10400 \mathrm{~kg} \cdot \mathrm{m}^{3} \cdot \mathrm{d}^{-1} ;[\mathrm{Fe}]=0.2 \mathrm{M}, \mathrm{T}=100^{\circ} \mathrm{C}\right)$ was analyzed by TEM (see Figure S11). There can be seen well-defined submicrometric rhombohedral MIL-53- $\mathrm{NH}_{2}$ particles. The resulting average particle size was of $330 \pm 50 \mathrm{~nm}(n=70)$ with additionally a monodisperse distribution $(\mathrm{PdI}=0.11)$, in accordance with previously observed in DLS $(260 \pm 70 \mathrm{~nm}$ Table S9). To the best of our knowledge, this is the first report of a MW-assisted synthesis of pure submicronic iron(III) aminoterephtalate MIL-53- $\mathrm{NH}_{2}$ up to date [29,32].

Considering the tests carried out in $\mathrm{HCl}\left([\mathrm{Fe}]=0.05 \mathrm{M}, \mathrm{T}=100{ }^{\circ} \mathrm{C}\right)$, the results unveiled the beneficial effect of the strong acid both (Figure S3): (i) on the crystallization of MIL-53- $\mathrm{NH}_{2}$; higher $\mathrm{HCl}$ amounts $(\geq 100 \mu \mathrm{L})$ favored the formation of MIL-53- $\mathrm{NH}_{2}$ over MIL-101- $\mathrm{NH}_{2}$; and (ii) on modulating and promoting the growth of a better crystallized MIL-101- $\mathrm{NH}_{2}$ (at lower acidic concentrations; $50 \mu \mathrm{L}$ ). This may be related to the better control of the kinetics rate reaction, associated to the deprotonation equilibrium of the carboxylate ligand $\left(\mathrm{H}_{2} \mathrm{BDC}-\mathrm{NH}_{2} \rightleftharpoons \mathrm{H}^{-} \mathrm{BDC}-\mathrm{NH}_{2}+\mathrm{H}^{+} \rightleftharpoons\right.$ BDC- $\mathrm{NH}_{2}+\mathrm{H}^{+}$). For a better analysis of the $\mathrm{HCl}$ presence, the water system $\mathrm{FeCl}_{3} / \mathrm{H}_{2} \mathrm{BDC}-\mathrm{NH}_{2}$ with and without acid at $100{ }^{\circ} \mathrm{C}$ and $[\mathrm{Fe}]=0.05 \mathrm{M}$ was further analyzed by TEM (Figure S11). Micrographs revealed that in the absence of $\mathrm{HCl}$, small rounded and undefined octahedra along the quaternary axis $(80 \pm 10 \mathrm{~nm}, n=150)$, corresponding to the MIL-101- $\mathrm{NH}_{2}$, were the predominant phase (Figure S11A). It is important to outstand the small particle size obtained. A previous report using lower concentrations $[\mathrm{Fe}]=0.02$, and longer times attained the phase with $\sim 300 \mathrm{~nm}$ (seen in TEM) [17]. Upon the addition of $100 \mu \mathrm{L}$ of acid, although the octahedra of MIL-101- $\mathrm{NH}_{2}$ seem better defined and well-faceted, its amount significantly decreased, increasing in the meantime the content of 
larger MIL-53- $\mathrm{NH}_{2}$ flakes $(190 \pm 25 \mathrm{~nm})$. Due to the mixture of phases and the absence of spherical particles, DLS measurements determined a high polydispersity $(\mathrm{PdI}>0.3)$ and bigger particle size than the one determined by TEM. Note here that the reaction in presence of $\mathrm{HCl}$ was almost complete, with yields of around $100 \%$ (see Table S11), but the increment in reaction volumes produces a decrease of the STY (from 8500 to $6500 \mathrm{~kg} \cdot \mathrm{m}^{3} \cdot \mathrm{d}^{-1}$, when in the presence of $200 \mu \mathrm{L}$ of acid). Despite this, a mixture of phases continued to appear up to high $\mathrm{HCl}$ volumes $(200 \mu \mathrm{L})$, which limits the accurate estimation of the proportion of each of them.

$\mathrm{EtOH}$ as reaction medium. As previously stated, $\mathrm{MIL}-88 \mathrm{~B}-\mathrm{NH}_{2}$ is the predominant phase in $\mathrm{EtOH}$ and might be an interesting candidate for industrial production (see Figure 4). Nevertheless, it is important to notice that increasing MOF precursors concentration did not directly imply higher yields. In the case of reactions at $150{ }^{\circ} \mathrm{C}$, the highest reaction yields were reached at lower concentration $(100 \mathrm{and}$ $85 \%$ at 0.02 and $0.05 \mathrm{M}$, respectively), being the more efficient reactions. However, considering the final production, despite the lower yields obtained with higher concentrated solutions ( $35 \%$ at $0.2 \mathrm{M}$ ), the maximum STY was performed at higher concentration $\left(6200 \mathrm{~kg} \cdot \mathrm{m}^{3} \cdot \mathrm{d}^{-1}\right)$. Therefore, there is a compromise solution to maximize reaction yield and the final product amount, that according to results is achieved at $\mathrm{T}=100^{\circ} \mathrm{C},[\mathrm{Fe}]=0.1 \mathrm{M}$ and $5 \mathrm{~min}$ of reaction. (see reaction yields and STY in Table S14).

\section{EtOH, $\mathrm{T}=150^{\circ} \mathrm{C}$}

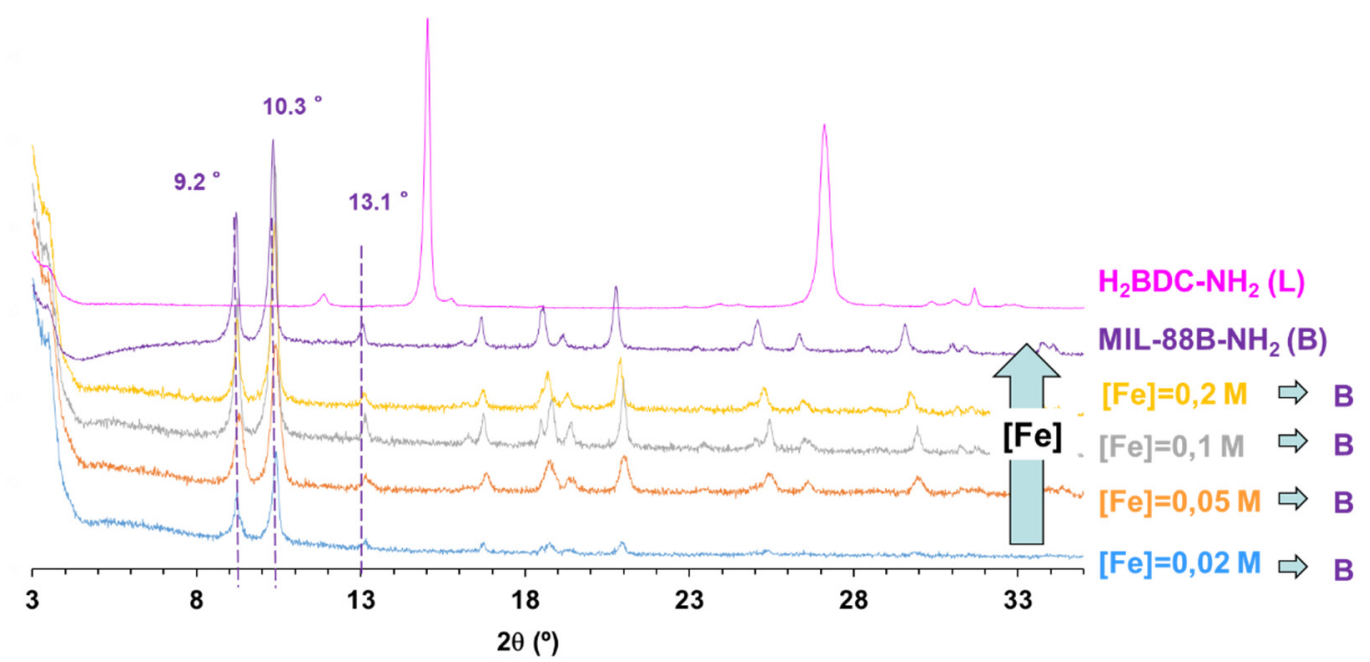

Figure 4. PXRD patterns for the $\mathrm{MW}$ investigation of the system $\mathrm{FeCl}_{3} \cdot 6 \mathrm{H}_{2} \mathrm{O} / \mathrm{H}_{2} \mathrm{BDC}-\mathrm{NH}_{2}$ in ethanol $\left(\mathrm{V} \mathrm{EtOH}=4 \mathrm{~mL}, \mathrm{~T}=150^{\circ} \mathrm{C}, \mathrm{t}=5 \mathrm{~min}\right.$ ) after activation with EtOH, compared to simulated MIL-88B-NH 2 (purple) and $\mathrm{H}_{2} \mathrm{BDC}-\mathrm{NH}_{2}$ (pink).

Due to its higher STY $\left(16000 \mathrm{~kg} \cdot \mathrm{m}^{-3} \cdot \mathrm{d}^{-1}\right)$ and crystallinity (see PXRD Figure S6), the sample synthetized at $\mathrm{T}=100^{\circ} \mathrm{C}$ and $[\mathrm{Fe}]=0.1 \mathrm{M}$ was selected for further analysis with TEM. TEM micrographs (Figure S12) exhibited the characteristic bipyramidal hexagonal prims of MIL-88B- $\mathrm{NH}_{2}$, confirming the phase determined previously by PXRD. The needles length (l) as determined by TEM, $1=110 \pm 20 \mathrm{~nm}$ $(n=100)$, is slightly smaller than the hydrodynamic radius viewed in DLS $(210 \pm 70 \mathrm{~nm})$. Particles have length: thickness ratio of $1.96 \pm 0.65$, being relatively symmetrical. Pure MIL-88B- $\mathrm{NH}_{2}$ has been previously obtained but using DMF as reaction medium [27]. Taking into account DMF toxicity, the protocol proposed in this work for the first time with $\mathrm{EtOH}$ provides a safer alternative for industrial production of MIL-88B- $\mathrm{NH}_{2}$.

Another interesting parameter for improving STY is reaction time. As a consequence, kinetics studies were carried out using two temperatures $\left(100\right.$ and $\left.150{ }^{\circ} \mathrm{C}\right)$ to better analyze this variable (see Tables S14 and S15). Results revealed that, although reaction yield grew with incrementing 
reaction time, maximum STY was performed just after $5 \mathrm{~min}$ of reaction $\left(16000\right.$ and $3300 \mathrm{~kg} \cdot \mathrm{m}^{3} \cdot \mathrm{d}^{-1}$ at 100 and $150{ }^{\circ} \mathrm{C}$, respectively).

DMF as reaction medium. As seen by the variety of phases obtained and characterized by PXRD, $\mathrm{DMF}$ is a complex reaction media. At concentrations below $0.2 \mathrm{M}$, iron trimers-based polymorphs (i.e., MIL-88B- $\mathrm{NH}_{2}$ and MIL-101- $\mathrm{NH}_{2}$ ) were favored, which seems to indicate that the formation of iron chains is only promoted in DMF at high concentrations. Regarding MIL-88B- $\mathrm{NH}_{2}$, even in mixture, was promoted with incrementing time within the 0.05-0.1 M range (see PXRD Figure S9). Formation of MIL-88B- $\mathrm{NH}_{2}$ over MIL-101- $\mathrm{NH}_{2}$ is not only modulated by the concentration, but also by the presence of strong acid as $\mathrm{HCl}$. Reaction time was fixed for this test to be $30 \mathrm{~min}$ to maximize reaction yield (see Table S17) using two different ligand:metal ratios. While the precursors ratio had no significant effect on the MOF formation, the presence of $\mathrm{HCl}$ affected the proportion of the resulting polymorphic phases, increasing the formation of MIL-88B- $\mathrm{NH}_{2}$ over MIL-101- $\mathrm{NH}_{2}$ (Figure S11). Furthermore, the presence of a strong acid produces MIL-88B- $\mathrm{NH}_{2}$ in DMF, while promoting MIL-53- $\mathrm{NH}_{2}$ in water, supporting the important role of the solvent on the nature of the obtained phases.

In addition, $\mathrm{HCl}$ modulates the crystal growth, procuring larger well-defined MIL-88B- $\mathrm{NH}_{2}$ crystals instead of MIL-101- $\mathrm{NH}_{2}$. (see Figures S10 and S13). Interestingly, MIL-88B- $\mathrm{NH}_{2}$ needles synthesized in DMF are 8 times longer than those formed in $\mathrm{EtOH}$ under similar conditions (without acid) and the length:thickness ratio is twofold times the EtOH ones $(4.55 \pm 1.42$ vs. $1.96 \pm 0.65$, respectively). This indicates once again the important role of the reaction media on the formation of the different phases and its effect on the crystallinity and particle size. Of no less importance is the modulation effect provided by the presence of $\mathrm{HCl}$ in the mixture, as not only procured a pure MIL-88B- $\mathrm{NH}_{2}$ phase, but also modulates particle growth, having a length:thickness ratio of $3.11 \pm 0.74$, and half the length as in pristine DMF $(410 \pm 45 \mathrm{~nm})$.

On the other hand, at high concentration $(0.2 \mathrm{M})$, both MIL-53- $\mathrm{NH}_{2}$ and MIL-101- $\mathrm{NH}_{2}$ present a good crystallinity, favoring the MIL-53- $\mathrm{NH}_{2}$ thermodynamic phase with increasing time. Due to its flexible character, this phase could be better identified after drying the sample at $160{ }^{\circ} \mathrm{C}$ and removing the remaining EtOH and DMF from the flexible porosity (see Figure S9).

Finally, final yield increases with reaction time (see Table S16). However, the mixture of phases limits further discussion.

Comparison of solvents: From these results, we can conclude that the reaction medium has the most relevant impact on the final phase attained due to several factors: solubility, de-protonation of the ligand (acid-base properties) and boiling $\mathrm{T}$ (and therefore final reaction pressure). As in our case, solubility of the $\mathrm{H}_{2} \mathrm{BDC}-\mathrm{NH}_{2}$ ligand is really limited in water, even under reactions conditions (MW-assisted heat and pressure) and seems to decrease the final reaction yield. Nevertheless, $\mathrm{H}_{2} \mathrm{O}$ is a particularly interesting solvent as is a cheap, safe and green solvent with no security associated protocols rewarding its storage neither its manipulation, which is of particular interest for commercial protocols. What is more, water has the lower environmental, safety and health (ESH) impact, according to solvent selection guides of companies such as GSK or Pfizer [33]. In addition, under the studied conditions, water was the sole solvent that gave both pure MIL-101- $\mathrm{NH}_{2}$ and MIL-53- $\mathrm{NH}_{2}$ phases with highest crystallinity and relatively good STY (3850 and $10400 \mathrm{~kg} \cdot \mathrm{m}^{-3} \cdot \mathrm{d}^{-1}$, respectively). While MIL-53- $\mathrm{NH}_{2}$ was obtained with water as reaction media for the first time, its polymorph, the MIL-68- $\mathrm{NH}_{2}$ still remains elusive under the studied variables.

$\mathrm{EtOH}$ is another interesting reaction medium, as is less harmful than other organic solvents and its recommended due to its low ESH. Compared to other organic solvents, with tendency to the crystallization of MIL-88B- $\mathrm{NH}_{2}$. In this work, it has been presented an outstanding STY of $16000 \mathrm{~kg} \cdot \mathrm{m}^{-3} \cdot \mathrm{d}^{-1}$ at soft reaction conditions $\left(\mathrm{T}=100{ }^{\circ} \mathrm{C}, \mathrm{t}=5 \mathrm{~min}\right)$, which exposes the beneficial use of MW-solvothermal assisted reaction for the industrial production of MIL-88B- $\mathrm{NH}_{2}$, which has demonstrated efficiency in applications such as photocatalysis, drug delivery and nanomotors [34-37]. In contrast, MIL-88B- $\mathrm{NH}_{2}$ particles with better crystallinity were produced in DMF, and should not be 
discarded as reaction medium only due to its known toxicity and cost compared with the previously mentioned solvents.

\section{Conclusions}

A thorough study has been carried out to analyze the influence of different reaction parameters on the MW assisted hydro/solvothermal synthesis of the $\mathrm{FeCl}_{3} / \mathrm{H}_{2} \mathrm{BDC}-\mathrm{NH}_{2}$ isoreticular hybrid compounds. Three pure phases of iron(III) aminoterephthalate MOFs have been obtained, namely: MIL-53- $\mathrm{NH}_{2}$, MIL-101- $\mathrm{NH}_{2}$ and MIL-88B-NH $\mathrm{NH}_{2}$. Characterization of the MOF phases by different solid-state techniques (PXRD, DLS, TEM) has enabled the identification of the reaction media as the main affecting variable of the MW assisted synthetic process. Importantly, the three different phases were obtained with water or either ethanol, both solvents with low ESH, relevant factor for MOF industrial production. Concentration of the MOF precursors and reaction temperature are other key parameters for phase selectivity. To the best of our knowledge, here is reported for the first time the MW assisted hydrothermal synthesis of under micron MIL-53(Fe)- $\mathrm{NH}_{2}$, opening the door for its industrial production.

Supplementary Materials: The following are available online at http://www.mdpi.com/1996-1944/13/6/1469/s1, Figure S1. PXRD patterns for the MW investigation of the system $\mathrm{FeCl}_{3} \cdot 6 \mathrm{H}_{2} \mathrm{O} / \mathrm{H}_{2} \mathrm{BDC}-\mathrm{NH}_{2} / \mathrm{HCl}$ in water $\left(\mathrm{V} \mathrm{H}_{2} \mathrm{O}=4 \mathrm{~mL}, \mathrm{~T}=100{ }^{\circ} \mathrm{C}, \mathrm{t}=5 \mathrm{~min}\right.$ ) after activation with $\mathrm{EtOH}$, compared to simulated MIL-101- $\mathrm{NH}_{2}$ (green), MIL-53- $\mathrm{NH}_{2}$ (red) and $\mathrm{H}_{2}$ BDC- $\mathrm{NH}_{2}$ (pink), Figure S2. PXRD patterns for the MW investigation of the system $\mathrm{FeCl}_{3} \cdot 6 \mathrm{H}_{2} \mathrm{O} / \mathrm{H}_{2} \mathrm{BDC}-\mathrm{NH}_{2} / \mathrm{HCl}$ in water $\left(\mathrm{V} \mathrm{H}_{2} \mathrm{O}=4 \mathrm{~mL}, \mathrm{~T}=150^{\circ} \mathrm{C}, \mathrm{t}=5 \mathrm{~min}\right)$ after activation with EtOH, compared to simulated MIL-101- $\mathrm{NH}_{2}$ (green), MIL-53- $\mathrm{NH}_{2}$ (red) and $\mathrm{H}_{2} \mathrm{BDC}-\mathrm{NH}_{2}$ (pink), Figure S3. PXRD patterns for the MW investigation of the system $\mathrm{FeCl}_{3} \cdot 6 \mathrm{H}_{2} \mathrm{O} / \mathrm{H}_{2} \mathrm{BDC}-\mathrm{NH}_{2} / \mathrm{HCl}$ in water $\left(\mathrm{V} \mathrm{H}_{2} \mathrm{O}=4 \mathrm{~mL}, \mathrm{~T}=100{ }^{\circ} \mathrm{C}, \mathrm{t}=5 \mathrm{~min}\right.$, $[\mathrm{Fe}]=0.05 \mathrm{M}$ ) after activation with EtOH, compared to simulated MIL-101-NH $\mathrm{NH}_{2}$ (green), MIL-53-NH $\mathrm{NH}_{2}$ (red) and H2BDC-NH $\mathrm{N}_{2}$ (pink), Figure S4. PXRD patterns for the MW investigation of the system $\mathrm{FeCl}_{3} \cdot 6 \mathrm{H}_{2} \mathrm{O} / \mathrm{H}_{2} \mathrm{BDC}-\mathrm{NH}_{2}$ in ethanol $\left(\mathrm{V} \mathrm{EtOH}=4 \mathrm{~mL}, \mathrm{~T}=150^{\circ} \mathrm{C},[\mathrm{Fe}]=0.2 \mathrm{M}, \mathrm{t}=5 \mathrm{~min}\right.$ ) after activation with $\mathrm{EtOH}$, compared to simulated MIL-88B-NH $\mathrm{H}_{2}$ (purple) and $\mathrm{H}_{2} \mathrm{BDC}-\mathrm{NH}_{2}$ (pink), Figure S5. PXRD patterns for the MW investigation of the system $\mathrm{FeCl}_{3} \cdot 6 \mathrm{H}_{2} \mathrm{O} / \mathrm{H}_{2} \mathrm{BDC}-\mathrm{NH}_{2}$ in ethanol $\left(\mathrm{V} \mathrm{EtOH}=4 \mathrm{~mL}, \mathrm{~T}=100{ }^{\circ} \mathrm{C}\right.$, $[\mathrm{Fe}]=0.1 \mathrm{M}$, ) after activation with EtOH, compared to simulated MIL-88B- $\mathrm{NH}_{2}$ (purple) and MIL-101-NH $\mathrm{NH}_{2}$ (green), Figure S6. PXRD patterns for the MW investigation of the system $\mathrm{FeCl}_{3} \cdot 6 \mathrm{H}_{2} \mathrm{O} / \mathrm{H}_{2} \mathrm{BDC}-\mathrm{NH}_{2}$ in ethanol $\left(\mathrm{V} \mathrm{EtOH}=4 \mathrm{~mL}, \mathrm{~T}=150{ }^{\circ} \mathrm{C},[\mathrm{Fe}]=0.1\right.$ $\mathrm{M}$ ) after activation with EtOH, compared to simulated MIL-88B-NH $\mathrm{N}_{2}$ (purple), Figure S7. PXRD patterns for the MW investigation of the system $\mathrm{FeCl}_{3} \cdot 6 \mathrm{H}_{2} \mathrm{O} / \mathrm{H}_{2} \mathrm{BDC}-\mathrm{NH}_{2}$ in ethanol $\left(\mathrm{V} \mathrm{EtOH}=4 \mathrm{~mL}, \mathrm{~T}=180{ }^{\circ} \mathrm{C},[\mathrm{Fe}]=\right.$ $0.1 \mathrm{M}$ ) after activation with EtOH, compared to simulated MIL-88B- $\mathrm{NH}_{2}$ (purple) and $\mathrm{Fe}_{2} \mathrm{O}_{3}$ (black), Figure S8. PXRD patterns for the MW investigation of the system $\mathrm{FeCl}_{3} \cdot 6 \mathrm{H}_{2} \mathrm{O} / \mathrm{H}_{2} \mathrm{BDC}-\mathrm{NH}_{2}$ in DMF (V DMF $=4 \mathrm{~mL}, \mathrm{~T}$ $=150{ }^{\circ} \mathrm{C}$, ligand:metal $=1: 1$ ) after activation with EtOH, compared to simulated MIL-88B-NH ${ }_{2}$ (purple) and MIL-101- $\mathrm{NH}_{2}$ (green), Figure S9. PXRD patterns for the MW investigation of the system $\mathrm{FeCl}_{3} \cdot 6 \mathrm{H}_{2} \mathrm{O} / \mathrm{H}_{2} \mathrm{BDC}-\mathrm{NH}_{2}$ in DMF (V DMF $=4 \mathrm{~mL}, \mathrm{~T}=150{ }^{\circ} \mathrm{C}$, ligand:metal $\left.=1: 1\right)$ after activation with EtOH and dried at $160{ }^{\circ} \mathrm{C}$, for better discriminating between the different Fe-BDC- $\mathrm{NH}_{2}$ MOF phases, Figure S10. PXRD patterns for the MW investigation of the system $\mathrm{FeCl}_{3} \cdot 6 \mathrm{H}_{2} \mathrm{O} / \mathrm{H}_{2} \mathrm{BDC}-\mathrm{NH}_{2} / \mathrm{HCl}$ in $\mathrm{DMF}\left(\mathrm{V} \mathrm{DMF}=4 \mathrm{~mL}, \mathrm{~T}=150^{\circ} \mathrm{C}, \mathrm{t}=30 \mathrm{~min}\right)$ after activation with EtOH, compared to simulated MIL-88B-NH $\mathrm{N}_{2}$ (purple) and MIL-101- $\mathrm{NH}_{2}$ (green), Figure S11. TEM micrographs for PXRD for the MW investigation of the system $\mathrm{FeCl}_{3} \cdot 6 \mathrm{H}_{2} \mathrm{O} / \mathrm{H}_{2} \mathrm{BDC}-\mathrm{NH}_{2} / \mathrm{HCl}$ in water $\left(\mathrm{V} \mathrm{H} \mathrm{H}_{2} \mathrm{O}\right.$ $=4 \mathrm{~mL}, \mathrm{t}=5 \mathrm{~min}$ ) after activation with EtOH: (A) $\mathrm{T}=100{ }^{\circ} \mathrm{C}, \mathrm{HCl} 0.1 \mathrm{M}=0 \mu \mathrm{L} ;(\mathbf{B}) \mathrm{T}=100{ }^{\circ} \mathrm{C}, \mathrm{HCl} 0.1 \mathrm{M}=$ $100 \mu \mathrm{L} ;(\mathbf{C}) \mathrm{T}=150^{\circ} \mathrm{C}, \mathrm{HCl} 0.1 \mathrm{M}=0 \mu \mathrm{L}$, Figure S12. TEM micrographs for PXRD for the MW investigation of the system $\mathrm{FeCl}_{3} \cdot 6 \mathrm{H}_{2} \mathrm{O} / \mathrm{H}_{2} \mathrm{BDC}-\mathrm{NH}_{2}$ in ethanol $\left(\mathrm{V} \mathrm{EtOH}=4 \mathrm{~mL}, \mathrm{t}=5 \mathrm{~min} \mathrm{~T}=100{ }^{\circ} \mathrm{C},[\mathrm{Fe}]=0.1 \mathrm{M}\right)$ after activation with EtOH scale bar $=1 \mu \mathrm{m}$, Figure S13. TEM micrographs for PXRD for the MW investigation of the system $\mathrm{FeCl}_{3} \cdot 6 \mathrm{H}_{2} \mathrm{O} / \mathrm{H}_{2} \mathrm{BDC}-\mathrm{NH}_{2} / \mathrm{HCl}$ in DMF $\left(\mathrm{V} \mathrm{DMF}=4 \mathrm{~mL}, \mathrm{t}=30 \mathrm{~min}, \mathrm{~T}=100{ }^{\circ} \mathrm{C}\right.$, ligand:metal $\left.=1: 1\right)$ after activation with EtOH: (A) HCl 0.1 M = $0 \mu \mathrm{L}$ (scale bar = $2 \mu \mathrm{m}$ ); (B) HCl $0.1 \mathrm{M}=100 \mu \mathrm{L}$ (scale bar =1 $\mu \mathrm{m}$ ), Table S1. Letter codes for the resulting products of the following MW synthesis, Table S2. Mass, mol and molar ratios, and dispensed amounts for the MW investigation of the system $\mathrm{FeCl}_{3} \cdot 6 \mathrm{H}_{2} \mathrm{O} / \mathrm{H}_{2} \mathrm{BDC}-\mathrm{NH}_{2} / \mathrm{HCl}$ in water $\left(\mathrm{V} \mathrm{H} \mathrm{H}_{2} \mathrm{O}=4 \mathrm{~mL}\right.$, $\mathrm{T}=100{ }^{\circ} \mathrm{C}, \mathrm{t}=5 \mathrm{~min}$ ). The resulting phases are indicated by the letter assigned in Table S1, Table S3. Mass, mol and molar ratios, and dispensed amounts for the MW investigation of the system $\mathrm{FeCl}_{3} \cdot 6 \mathrm{H}_{2} \mathrm{O} / \mathrm{H}_{2} \mathrm{BDC}-\mathrm{NH}_{2} / \mathrm{HCl}$ in water $\left(\mathrm{V} \mathrm{H}_{2} \mathrm{O}=4 \mathrm{~mL}, \mathrm{~T}=150^{\circ} \mathrm{C}, \mathrm{t}=5 \mathrm{~min}\right.$ and $\left.{ }^{(\bullet)} \mathrm{t}=30 \mathrm{~min}\right)$. The resulting phases are indicated by the letter assigned in Table S1, Table S4. Mass, mol and molar ratios, and dispensed amounts for the MW investigation of the system $\mathrm{FeCl}_{3} \cdot 6 \mathrm{H}_{2} \mathrm{O} / \mathrm{H}_{2} \mathrm{BDC}-\mathrm{NH}_{2}$ in ethanol ( $\left.\mathrm{VtOH}=4 \mathrm{~mL} . \mathrm{T}=150{ }^{\circ} \mathrm{C} . \mathrm{t}=5 \mathrm{~min}\right)$. The resulting phases are indicated by the letter assigned in Table S1, Table S5. Mass, mol and molar ratios, and dispensed amounts for the MW investigation of assigned in Table S1. the system $\mathrm{FeCl}_{3} \cdot 6 \mathrm{H}_{2} \mathrm{O} / \mathrm{H}_{2} \mathrm{BDC}-\mathrm{NH}_{2}$ in ethanol $(\mathrm{V} \mathrm{EtOH}=4 \mathrm{~mL}$. $\mathrm{T}=150^{\circ} \mathrm{C} . \mathrm{t}=5 \mathrm{~min}$ ). The resulting phases are indicated by the letter assigned in Table S1, Table S6. Mass, mol and molar ratios, and dispensed amounts for the MW investigation of the system $\mathrm{FeCl}_{3} \cdot 6 \mathrm{H}_{2} \mathrm{O} / \mathrm{H}_{2} \mathrm{BDC}-\mathrm{NH}_{2}$ in ethanol ( $\mathrm{V} \mathrm{EtOH}=4 \mathrm{~mL}$, [Fe] =0.1 M, ligand:metal = 1:1). The resulting phases are indicated by the letter assigned in Table S1, Table S7. Mass, mol and molar ratios, and dispensed amounts for the MW investigation of the system $\mathrm{FeCl}_{3} \cdot 6 \mathrm{H}_{2} \mathrm{O} / \mathrm{H}_{2} \mathrm{BDC}-\mathrm{NH}_{2}$ in DMF (V DMF $=4 \mathrm{~mL} . \mathrm{T}=150{ }^{\circ} \mathrm{C}$. ligand:metal = 1:1). The resulting phases are indicated by the letter assigned in Table S1, Table S8. Mass, mol and molar ratios, and dispensed amounts for the 
MW investigation of the system $\mathrm{FeCl}_{3} \cdot 6 \mathrm{H}_{2} \mathrm{O} / \mathrm{H}_{2} \mathrm{BDC}-\mathrm{NH}_{2} / \mathrm{HCl}$ in DMF (V DMF $=4 \mathrm{~mL} \cdot \mathrm{T}=150{ }^{\circ} \mathrm{C} \cdot \mathrm{t}=5 \mathrm{~min}$ ). The resulting phases are indicated by the letter assigned in Table S1, Table S9. Particle size and reaction yield for the MW investigation of the system $\mathrm{FeCl}_{3} \cdot 6 \mathrm{H}_{2} \mathrm{O} / \mathrm{H}_{2} \mathrm{BDC}-\mathrm{NH}_{2}$ in water $\left(\mathrm{V} \mathrm{H}_{2} \mathrm{O}=4 \mathrm{~mL}, \mathrm{~T}=100{ }^{\circ} \mathrm{C}, \mathrm{t}=5 \mathrm{~min}\right.$, Table S10. Particle size and reaction yield for the MW investigation of the system $\mathrm{FeCl}_{3} \cdot 6 \mathrm{H}_{2} \mathrm{O} / \mathrm{H}_{2} \mathrm{BDC}-\mathrm{NH}_{2}$ in water $\left(\mathrm{V} \mathrm{H}_{2} \mathrm{O}=4 \mathrm{~mL}, \mathrm{~T}=150^{\circ} \mathrm{C}, \mathrm{t}=5 \mathrm{~min}\right)$, Table S11. Particle size and reaction yield for the $\mathrm{MW}$ investigation of the system $\mathrm{FeCl}_{3} \cdot 6 \mathrm{H}_{2} \mathrm{O} / \mathrm{H}_{2} \mathrm{BDC}-\mathrm{NH}_{2} / \mathrm{HCl}$ in water $\left([\mathrm{Fe}]=0.05 \mathrm{M}, \mathrm{V} \mathrm{H}_{2} \mathrm{O}=4 \mathrm{~mL}, \mathrm{~T}=100{ }^{\circ} \mathrm{C}, \mathrm{t}=5 \mathrm{~min}\right)$, Table S12. Particle size and reaction yield for the MW investigation of the system $\mathrm{FeCl}_{3} \cdot 6 \mathrm{H}_{2} \mathrm{O} / \mathrm{H}_{2} \mathrm{BDC}-\mathrm{NH}_{2}$ in ethanol $(\mathrm{V}$ $\mathrm{EtOH}=4 \mathrm{~mL}, \mathrm{~T}=150{ }^{\circ} \mathrm{C}, \mathrm{t}=5 \mathrm{~min}$ ), Table S13. Particle size and reaction yield for the $\mathrm{MW}$ investigation of the system $\mathrm{FeCl}_{3} \cdot 6 \mathrm{H}_{2} \mathrm{O} / \mathrm{H}_{2} \mathrm{BDC}-\mathrm{NH}_{2}$ in ethanol $\left(\mathrm{V} \mathrm{EtOH}=4 \mathrm{~mL}, \mathrm{~T}=150{ }^{\circ} \mathrm{C}, \mathrm{t}=5 \mathrm{~min},[\mathrm{Fe}]=0.2 \mathrm{M}\right)$, Table S14. Particle size and reaction yield for the MW investigation of the system $\mathrm{FeCl}_{3} \cdot 6 \mathrm{H}_{2} \mathrm{O} / \mathrm{H}_{2} \mathrm{BDC}-\mathrm{NH}_{2}$ in ethanol (V $\left.\mathrm{EtOH}=4 \mathrm{~mL}, \mathrm{~T}=100^{\circ} \mathrm{C},[\mathrm{Fe}]=0.1 \mathrm{M}\right)$, Table S15. Particle size and reaction yield for the MW investigation of the system $\mathrm{FeCl}_{3} \cdot 6 \mathrm{H}_{2} \mathrm{O} / \mathrm{H}_{2} \mathrm{BDC}-\mathrm{NH}_{2}$ in ethanol (V EtOH $=4 \mathrm{~mL}, \mathrm{~T}=150{ }^{\circ} \mathrm{C}$, [Fe] $\left.=0.1 \mathrm{M}\right)$, Table S16. Particle size and reaction yield for the MW investigation of the system $\mathrm{FeCl}_{3} \cdot 6 \mathrm{H}_{2} \mathrm{O} / \mathrm{H}_{2} \mathrm{BDC}-\mathrm{NH}_{2}$ in DMF $(\mathrm{V} \mathrm{DMF}=4 \mathrm{~mL}$, $\mathrm{T}=150{ }^{\circ} \mathrm{C}$, ligand:metal $=1: 1$ ), Table S17. Particle size and reaction yield for the MW investigation of the system $\mathrm{FeCl}_{3} \cdot 6 \mathrm{H}_{2} \mathrm{O} / \mathrm{H}_{2} \mathrm{BDC}-\mathrm{NH}_{2} / \mathrm{HCl}$ in DMF $\left(\mathrm{V} \mathrm{DMF}=4 \mathrm{~mL}, \mathrm{~T}=150{ }^{\circ} \mathrm{C}, \mathrm{t}=30 \mathrm{~min},[\mathrm{Fe}]=0.05\right)$.

Author Contributions: Conceptualization, P.H. and A.A.-V.; methodology, P.H., D.A. and A.A.-V.; formal analysis, P.H. and A.A.-V.; writing — original draft preparation, A.A.-V.; writing—review and editing, P.H., D.A. and A.A.-V.; funding acquisition, P.H. All authors have read and agreed to the published version of the manuscript.

Funding: This research was funded by Raphuel project (ENE2016-79608-C2-1-R, MINECO-AEI/FEDER, UE), and the Ramón Areces Foundation project H+MOFs. PH acknowledges the Spanish Ramón y Cajal Programme (2014-15039). DA acknowledges the financial support through the Retos Project from MINECO with reference MAT2017-84385-R for funding. The authors also thank the CNME for the support and facilities.

Acknowledgments: Authors thank to Ayoub Benckhlafa Akil for his technical support in the synthesis and characterization tasks.

Conflicts of Interest: The authors declare no conflict of interest. The funders had no role in the design of the study; in the collection, analyses, or interpretation of data; in the writing of the manuscript, or in the decision to publish the results.

\section{References}

1. Férey, G. Hybrid porous solids: Past, present, future. Chem. Soc. Rev. 2008, 37, 191-214. [CrossRef]

2. Maurin, G.; Serre, C.; Cooper, A.; Férey, G. The new age of MOFs and of their porous-related solids. Chem. Soc. Rev. 2017, 46, 3104-3107. [CrossRef] [PubMed]

3. Furukawa, H.; Ko, N.; Go, Y.B.; Aratani, N.; Choi, S.B.; Choi, E.; Yazaydin, A.Ö.; Snurr, R.Q.; O’Keeffe, M.; $\mathrm{Kim}, \mathrm{J}$; et al. Ultrahigh porosity in metal-organic frameworks. Science 2010, 329, 424-428. [CrossRef] [PubMed]

4. Timofeeva, M.N.; Panchenko, V.N.; Khan, N.A.; Hasan, Z.; Prosvirin, I.P.; Tsybulya, S.V.; Jhung, S.H. Isostructural metal-carboxylates MIL-100(M) and MIL-53(M) (M: V, Al, Fe and Cr) as catalysts for condensation of glycerol with acetone. Appl. Catal. A Gen. 2017, 529, 167-174. [CrossRef]

5. Blandez, J.F.; Santiago-Portillo, A.; Navalón, S.; Giménez-Marqués, M.; Álvaro, M.; Horcajada, P.; García, H. Influence of functionalization of terephthalate linker on the catalytic activity of UiO-66 for epoxide ring opening. J. Mol. Catal. A Chem. 2016, 425, 332-339. [CrossRef]

6. Furukawa, H.; Cordova, K.E.; O'Keeffe, M.; Yaghi, O.M. The chemistry and applications of metal-organic frameworks. Science 2013, 341, 1230444. [CrossRef] [PubMed]

7. Lin, K.-S.; Adhikari, A.K.; Ku, C.-N.; Chiang, C.-L.; Kuo, H. Synthesis and characterization of porous HKUST-1 metal organic frameworks for hydrogen storage. Int. J. Hydrog. Energy 2012, 37, 13865-13871. [CrossRef]

8. Zhang, T.; Lin, W. Metal-organic frameworks for artificial photosynthesis and photocatalysis. Chem. Soc. Rev. 2014, 43, 5982-5993. [CrossRef]

9. Falcaro, P.; Ricco, R.; Yazdi, A.; Imaz, I.; Furukawa, S.; Maspoch, D.; Ameloot, R.; Evans, J.D.; Doonan, C.J. Application of Metal and Metal Oxide Nanoparticles@MOFs. Coord. Chem Rev. 2015, 307. [CrossRef]

10. Horcajada, P.; Gref, R.; Baati, T.; Allan, P.K.; Maurin, G.; Couvreur, P.; Férey, G.; Morris, R.E.; Serre, C. Metal-Organic Frameworks in Biomedicine. Chem. Rev. 2012, 112, 1232-1268. [CrossRef]

11. Rojas, S.; Arenas-Vivo, A.; Horcajada, P. Metal-organic frameworks: A novel platform for combined advanced therapies. Coord. Chem. Rev. 2019, 388, 202-226. [CrossRef]

12. Pettinari, C.; Marchetti, F.; Mosca, N.; Tosi, G.; Drozdov, A. Application of Metal-organic Frameworks. Polym. Int. 2017, 66, 731-744. [CrossRef] 
13. Zlotea, C.; Phanon, D.; Mazaj, M.; Heurtaux, D.; Guillerm, V.; Serre, C.; Horcajada, P.; Devic, T.; Magnier, E.; Cuevas, F.; et al. Effect of NH2 and CF3 functionalization on the hydrogen sorption properties of MOFs. J. Chem. Soc. Dalt. Trans. 2011, 40, 4879-4881. [CrossRef] [PubMed]

14. Devic, T.; Horcajada, P.; Serre, C.; Salles, F.; Maurin, G.; Moulin, B.; Heurtaux, D.; Clet, G.; Vimont, A.; Grenéche, J.M.; et al. Functionalization in flexible porous solids: Effects on the pore opening and the host-guest interactions. J. Am. Chem. Soc. 2010, 132, 1127-1136. [CrossRef] [PubMed]

15. Fateeva, A.; Horcajada, P.; Devic, T.; Serre, C.; Marrot, J.; Grenèche, J.-M.; Morcrette, M.; Tarascon, J.-M.; Maurin, G.; Férey, G. Synthesis, Structure, Characterization, and Redox Properties of the Porous MIL-68(Fe) Solid. Eur. J. Inorg. Chem. 2010, 2010, 3789-3794. [CrossRef]

16. Horcajada, P.; Salles, F.; Wuttke, S.; Devic, T.; Heurtaux, D.; Maurin, G.; Vimont, A.; Daturi, M.; David, O.; Magnier, E.; et al. How linker's modification controls swelling properties of highly flexible iron(III) dicarboxylates MIL-88. J. Am. Chem. Soc. 2011, 133, 17839-17847. [CrossRef]

17. Horcajada, P.; Chevreau, H.; Heurtaux, D.; Benyettou, F.; Salles, F.; Devic, T.; Garcia-Marquez, A.; Yu, C.; Lavrard, H.; Dutson, C.L.; et al. Extended and functionalized porous iron(iii) tri- or dicarboxylates with MIL-100/101 topologies. Chem. Commun. 2014, 50, 6872-6874. [CrossRef]

18. Xia, Q.; Wang, H.; Huang, B.; Yuan, X.; Zhang, J.; Zhang, J.; Jiang, L.; Xiong, T.; Zeng, G. State-of-the-Art Advances and Challenges of Iron-Based Metal Organic Frameworks from Attractive Features, Synthesis to Multifunctional Applications. Small 2018, 15, 1803088. [CrossRef]

19. Yilmaz, B.; Trukhan, N.; Müller, U. Industrial outlook on zeolites and metal organic frameworks. Cuihua Xuebao/Chin. J. Catal. 2012, 33, 3-10. [CrossRef]

20. Klinowski, J.; Almeida Paz, F.A.; Silva, P.; Rocha, J. Microwave-assisted synthesis of metal-organic frameworks. Dalt. Trans. 2011, 40, 321-330. [CrossRef]

21. Nüchter, M.; Ondruschka, B.; Bonrath, W.; Gum, A. Microwave assisted synthesis - a critical technology overview. Green Chem. 2004, 6, 128-141. [CrossRef]

22. Morschhäuser, R.; Krull, M.; Kayser, C.; Boberski, C.; Bierbaum, R.; Püschner, P.A.; Glasnov, T.N.; Kappe, C.O. Microwave-assisted continuous flow synthesis on industrial scale. Green Process Synth. 2012, 1, 281-290. [CrossRef]

23. Nagahata, R.; Takeuchi, K. Encouragements for the Use of Microwaves in Industrial Chemistry. Chem. Rec. 2019, 19, 51-64. [CrossRef] [PubMed]

24. Santagada, V.; Frecentese, F.; Perissutti, E.; Fiorino, F.; Severino, B.; Caliendo, G. Microwave Assisted Synthesis: A New Technology in Drug Discovery. Mini-Rev. Med. Chem. 2012, 9, 340-358. [CrossRef]

25. Lee, E.J.; Bae, J.; Choi, K.M.; Jeong, N.C. Exploiting Microwave Chemistry for Activation of Metal-Organic Frameworks. ACS Appl. Mater. Interfaces 2019, 11, 34989-34996. [CrossRef]

26. Haque, E.; Khan, N.A.; Park, J.H.; Jhung, S.H. Synthesis of a Metal-Organic Framework Material, Iron Terephthalate, by Ultrasound, Microwave, and Conventional Electric Heating: A Kinetic Study. Chem. A Eur. J. 2010, 16, 1046-1052. [CrossRef]

27. Ma, M.; Bétard, A.; Weber, I.; Al-Hokbany, N.S.; Fischer, R.A.; Metzler-Nolte, N. Iron-based metal-organic frameworks MIL-88B and NH2-MIL-88B: High quality microwave synthesis and solvent-induced lattice "breathing". Cryst. Growth Des. 2013, 13, 2286-2291. [CrossRef]

28. Dong, W.; Liu, X.; Shi, W.; Huang, Y. Metal-organic framework MIL-53(Fe): Facile microwave-assisted synthesis and use as a highly active peroxidase mimetic for glucose biosensing. RSC Adv. 2015, 5, 17451-17457. [CrossRef]

29. Guo, W.; Sun, W.; Lv, L.-P.; Kong, S.; Wang, Y. Microwave-Assisted Morphology Evolution of Fe-Based Metal-Organic Frameworks and Their Derived $\mathrm{Fe}_{2} \mathrm{O}_{3}$ Nanostructures for Li-Ion Storage. ACS Nano. 2017, 11, 4198-4205. [CrossRef]

30. Taylor-Pashow, K.M.L.; Della Rocca, J.; Xie, Z.; Tran, S.; Lin, W. Postsynthetic modifications of iron-carboxylate nanoscale metal-organic frameworks for imaging and drug delivery. J. Am. Chem. Soc. 2009, 131, 14261-14263. [CrossRef]

31. Farrusseng, D. Metal-Organic Frameworks: Applications from Catalysis to Gas Storage; Farruseng, D., Ed.; Wiley-VCH: Weinheim, Germany, 2011.

32. Soni, A.K.; Dey, R.; Rai, V.K. Stark sublevels in Tm3+-Yb3+ codoped Na2Y2B2O7 nanophosphor for multifunctional applications. RSC Adv. 2015, 5, 34999-35009. [CrossRef]

33. Clarke, C.J.; Tu, W.C.; Levers, O.; Bröhl, A.; Hallett, J.P. Green and Sustainable Solvents in Chemical Processes. Chem. Rev. 2018, 118, 747-800. [CrossRef] [PubMed] 
34. Dao, X.Y.; Guo, J.H.; Wei, Y.P.; Guo, F.; Liu, Y.; Sun, W.Y. Solvent-free photoreduction of CO2 to CO catalyzed by Fe-MOFs with superior selectivity. Inorg. Chem. 2019, 58, 8517-8524. [CrossRef] [PubMed]

35. Horcajada, P.; Chalati, T.; Serre, C.; Gillet, B.; Sebrie, C.; Baati, T.; Eubank, J.F.; Heurtaux, D.; Clayette, P.; Kreuz, C.; et al. Porous metal-organic-framework nanoscale carriers as a potential platform for drug delivery and imaging. Nat. Mater. 2010, 9, 172-178. [CrossRef] [PubMed]

36. Claes, B.; Boudewijns, T.; Muchez, L.; Hooyberghs, G.; Van der Eycken, E.V.; Vanderleyden, J.; Steenackers, H.P.; De Vos, D.E. Smart Metal-Organic Framework Coatings: Triggered Antibiofilm Compound Release. ACS Appl. Mater. Interfaces 2017, 9, 4440-4449. [CrossRef] [PubMed]

37. Troyano, J.; Carné-Sánchez, A.; Pérez-Carvajal, J.; León-Reina, L.; Imaz, I.; Cabeza, A.; Maspoch, D.A. A Self-Folding Polymer Film Based on Swelling Metal-Organic Frameworks. Angew. Chem. Int. Ed. 2018, 57, 15420-15424. [CrossRef]

(C) 2020 by the authors. Licensee MDPI, Basel, Switzerland. This article is an open access article distributed under the terms and conditions of the Creative Commons Attribution (CC BY) license (http://creativecommons.org/licenses/by/4.0/). 